\title{
A (RE)CONSTRUÇÃO SOCIAL DA IDENTIDADE FEMININA: DESAFIOS DOS TCS NA IMPLEMENTAÇÃO DO ODS 5
}

\author{
(Re)construction of female social identity: the auditors count challenge to \\ implement SDG 5
}

Sabrina Nunes Iocken

\author{
Luciane Beiro de Souza Machado
}

[...] porque essa história nunca foi contada como merece. Michelli Dean

Resumo: $\mathrm{O}$ artigo aborda a necessidade de (re) construção, pelos sujeitos sociais, da identidade feminina, de modo a internalizar como antissocial a cultura da desigualdade. O estudo está centrado no ODS 5, que compreende tanto a dimensão negativa-repressiva, como as metas relacionadas à dimensão positivo-inclusiva da participação das mulheres nas esferas de poder. A percepção da natureza transversal da igualdade de gênero é enfatizada face ao efeito multiplicador e à sua capacidade de promoção do crescimento econômico e do desenvolvimento sustentável da sociedade como um todo. O recorte do estudo aponta para o papel dos Tribunais de Contas no processo de monitoramento da implementação do ODS 5 como instrumento acelerador do processo de articulação e integração das políticas públicas destinadas a dar cumprimento à Agenda 2030. Ainda que potencialmente indutores da implementação do ODS 5, constata-se que há deficiências que devem ser superadas, relacionadas à estrutura de articulação entre órgãos, aos processos de monitoramento e de avaliação e aos sistemas de dados. Ademais, inexiste, no âmbito dos Tribunais de Contas, qualquer diretriz nacional que esteja atrelada ao ODS 5.

Palavras-chave: Identidade feminina. Igualdade de gênero. ODS 5. Tribunal de Contas.

\begin{abstract}
The article approaches the need to (re) build female identity aiming internalized the culture of gender inequality as antisocial behavior. The study focuses on Sustainable Development Goals 5 (SDG 5), which regards a negative-repressive and positive-inclusive dimensions of women's participation in the spheres of power. The cross-cutting nature of gender equality is emphasized in the face of the multiplier of effects and the capacity to make economic growth and sustainable development of society as a whole. The study points out to the Audit Courts' role in the process of monitoring the implementation of SDG 5, as an accelerating tool for articulating and integrating public policies to comply with the 2030 Agenda. Although the Audit Courts are potentially inductors for the implementation of SDG 5, it is verified that there are deficiencies that must be overcome, which are related to the articulation structure among institutions and bodies; to the monitoring and evaluation processes; and data systems. In addition, there are no national guidelines in the scope of the Audit Courts that are linked to the SDG 5.
\end{abstract}

Keywords: Female identity. Gender equality. SDG 5. Audit Courts.

\footnotetext{
${ }^{1}$ Sobre a história dessas mulheres, vide DEAN, Michelle. Afiadas: as mulheres que fizeram da opinião uma arte. São Paulo: Todavia, 2018, p. 299.
}

Artigo recebido em 22 jul. 2019 e aprovado em 19 ago. 2019. 


\section{Introdução}

Afiadas foi o título escolhido por Michelle Dean para o livro que reúne a história de "mulheres afiadas" que marcaram o século XX, momento em que a política, a cultura e mesmo os registros históricos não tinham a menor disposição para sequer ouvir as opiniões femininas sobre assunto algum (DEAN, 2018, p. 9).

Um século depois, percebe-se que a estrutura patriarcal de exclusão ainda resiste nas sociedades contemporâneas, o que é facilmente percebido em toda a estrutura da organização social, da produção e consumo à política, à legislação e à cultura. Um retrato social que, segundo as lições do sociólogo espanhol Manuel Castells, é resultante da desigualdade imposta pelo patriarcalismo, em que os relacionamentos interpessoais e, por via de consequência, a própria personalidade, são marcados pela autoridade masculina (CASTELLS, 2013, p. 169).

Igualmente afiado é o desafio assumido pelo governo brasileiro com relação à internalização do Objetivo do Desenvolvimento Sustentável 5 (ODS 5) da Agenda 2030 da ONU, pois pressupõe alcançar, na próxima década, frisa-se em um pouco mais de 10 anos, a igualdade entre homens e mulheres ${ }^{2}$.

O obstáculo mais sólido desse processo de transformação está enraizado na própria subjetividade humana. A percepção de qual é o papel da mulher, tanto no espaço público quanto no privado, é resultante de uma construção social. Não se pode deixar de considerar que a maneira como agimos reflete a forma como sentimos e pensamos. Transpor essa barreira e, portanto, o sistema inconscientemente replicado da autoridade masculina ${ }^{3}$, pressupõe a reconstrução das relações sociais sob o prisma igualitário em relação ao exercício de direitos ${ }^{4}$, o que exige tanto uma mudança cultural coletiva, como uma mudança individual atrelada à necessidade de reprogramar a própria mente.

${ }^{2} \mathrm{O}$ texto enfatiza o sentimento de urgência para a implementação dos ODS. Em apoio à Agenda 2030, a ONU Mulheres lançou a iniciativa global "Por um planeta 50-50" em 2030, a partir de compromissos concretos assumidos por mais de 90 países.

${ }^{3}$ Sobre a crise da estrutura e dos valores da família patriarcal, Castells aponta para o fim do modelo de família não apenas da família nuclear (um artefato moderno), mas a família baseada no domínio patriarcal, que tem predominado há milênios. (CASTELLS, 2013, p. 174)

${ }^{4}$ Ainda que distintos o comportamento humano e o exercício das opções individuais, o que se pretende é a igualdade de direitos entre gêneros.

Resenha Eleitoral (Florianópolis), v. 23, n. 1, p. 71-88, 2019 
Por certo que o primeiro passo, que é o de reconhecer a desigualdade, não elimina os problemas decorrentes da discriminação, do abuso e da violência contra as mulheres. A atuação repressiva, subsidiada pelo aparato normativo-jurídico, tem evidenciado avanços significativos, como os explicitados nas Leis n. 11.340/06, n. 13.104/15, n. 13.718/18, dentre outras. No entanto, ainda se mostra ineficiente a implementação das políticas públicas necessárias para dar cumprimento aos comandos legais.

Ademais, o processo de conscientização do papel da mulher na sociedade tem alcançado novos contornos que superam a dimensão negativo-repressiva, induzindo também a uma atuação positiva, seja na esfera política, econômica ou social. Trata-se da faceta positivo-inclusiva de participação da mulher nas esferas de poder, fundamental para o processo de reconstrução social da "identidade feminina” (CASTELLS, 2013, p. 172).

O recorte deste estudo direciona o olhar para as instituições de controle com o objetivo de verificar como está sendo fiscalizada a preparação do governo brasileiro para a implementação das políticas públicas direcionadas para dar cumprimento aos Objetivos do Desenvolvimento Sustentável (ODS). De modo mais específico, como as instituições de controle estão inserindo em suas fiscalizações a verificação do atendimento do ODS 5. A existência de 33 Tribunais de Contas em todo o País constitui um instrumental valioso nesse processo (IOCKEN, 2019), devendo subsidiar a preparação e a implementação dos ODS da Agenda 2030, contribuindo para isso.

Atento a esse movimento, o Tribunal de Contas da União (TCU) aderiu ao "Programa Auditando os Objetivos de Desenvolvimento Sustentável”, da Organização Internacional de Entidades Fiscalizadoras Superiores (INTOSAI), e instaurou um processo de auditoria operacional para avaliar a preparação do governo brasileiro na implementação do ODS 5 da Agenda 2030.

Nesse contexto, o objetivo específico deste estudo é o de oferecer alguns quadros analíticos que possam contribuir para sistematizar e organizar a programação de fiscalização no âmbito dos demais Tribunais de Contas. A temática foi desenvolvida a partir de algumas afirmações teóricas sobre aspectos-chave da diretriz estabelecida no quinto objetivo do desenvolvimento sustentável da Organização das Nações Unidas (ONU). 
A percepção da desigualdade de gênero como um problema não "natural", e sim como um problema público antissocial, demanda políticas públicas integradas e transversais, não apenas direcionadas a combater as formas de violência, mas também a promover e a incluir a mulher no espaço público decisório. É nesse contexto que as diretrizes da ONU, sob a perspectiva positiva ou a inclusiva, apontam também pela inserção da mulher nas relações de poder. Estabelece-se, assim, um novo contrato social entre homens e mulheres, como aponta Salazar (SALAZAR, 2018).

A proposta deste estudo é, portanto, a de contribuir para o "desafio afiado" imposto pelo ODS 5, através da participação dos Tribunais de Contas no esforço coordenado e articulado entre os entes e os órgãos governamentais para a implementação de um Programa de Estado de longo prazo que proporcione relações simétricas entre homens e mulheres.

\section{A decisão que antecedeu as políticas públicas: a nova identidade feminina}

A escolha das políticas públicas não coincide necessariamente com os problemas sociais. A definição de quais problemas merecem a atenção do governo é decorrente de uma decisão política prévia de inclusão ou não na agenda pública. Deve-se ter em conta que o acesso à agenda pública não está atrelado à existência de problemas "naturais". Ao contrário, a definição da agenda é o produto das forças políticas que se formam em torno de um determinado problema. O cientista político Pierre Muller, em sua obra Les politiques publiques (2015), enfatiza que a transformação de um problema em objeto de intervenção política é sempre o resultado de um trabalho específico de atores políticos (MULLER, 2015).

O mesmo ocorre no que diz respeito à questão da desigualdade em relação à mulher. Ainda que a relação de desigualdade sempre estivesse presente na história da humanidade, tal questão era compreendida como problema natural e inerente à relação humana, sem que necessariamente se constituísse em problema público, sob o qual a atuação do Estado devesse impor regras específicas para a garantia da igualdade de gênero.

A decisão política internacional já alterou essa visão quando do estabelecimento dos oito Objetivos de Desenvolvimento do Milênio (ODM), após a Cúpula do Milênio das Nações Unidas, realizada em 2000, na qual os 
191 Estados Membros da ONU comprometeram-se a "promover a igualdade de gênero e empoderar as mulheres" até o ano de 2015.

Decorridos quinze anos, a questão da igualdade de gênero foi novamente inserida na Agenda 2030, aprovada em Assembleia Geral da ONU e ratificada pelo Governo Brasileiro, constituindo-se no Objetivo de Desenvolvimento Sustentável 5 (ODS 5), que estabelece como diretriz "alcançar a igualdade de gênero e empoderar todas as mulheres e meninas". Busca-se a consecução de nove metas principais ${ }^{5}$, classificadas como finalísticas, ou seja, que têm objeto diretamente relacionado para o alcance do ODS (metas 5.1 a 5.6), ou como metas de implementação, que se referem a recursos humanos, financeiros, tecnológicos e de governança necessários para o alcance do ODS (metas 5.a a 5.c).

Há diversos órgãos governamentais responsáveis pelo monitoramento de ações que contribuam para o alcance dessas metas, como a Secretaria Nacional de Políticas para Mulheres, Secretaria de Governo, Judiciário, Legislativo e todos os Ministérios do Executivo.

Perquirir quais são as diretrizes que devem ser incluídas no âmbito do controle externo para induzir ao atendimento ao ODS 5 e às metas a ele vinculadas é exatamente o ponto de inflexão deste estudo.

\footnotetext{
${ }^{5}$ São elas: 5.1 Acabar com todas as formas de discriminação contra todas as mulheres e meninas em toda parte; 5.2 Eliminar todas as formas de violência contra todas as mulheres e meninas nas esferas públicas e privadas, incluindo o tráfico e a exploração sexual e de outros tipos; 5.3 Eliminar todas as práticas nocivas, como os casamentos prematuros, forçados e de crianças e mutilações genitais femininas; 5.4 Reconhecer e valorizar o trabalho de assistência e doméstico não remunerado, por meio da disponibilização de serviços públicos, infraestrutura e políticas de proteção social, bem como a promoção da responsabilidade compartilhada dentro do lar e da família, conforme os contextos nacionais; 5.5 Garantir a participação plena e efetiva das mulheres e a igualdade de oportunidades para a liderança em todos os níveis de tomada de decisão na vida política, econômica e pública; 5.6 Assegurar o acesso universal à saúde sexual e reprodutiva e os direitos reprodutivos, como acordado em conformidade com o Programa de Ação da Conferência Internacional sobre População e Desenvolvimento e com a Plataforma de Ação de Pequim e os documentos resultantes de suas conferências de revisão; 5.a Empreender reformas para dar às mulheres direitos iguais aos recursos econômicos, bem como o acesso à propriedade e o controle sobre a terra e outras formas de propriedade, serviços financeiros, herança e os recursos naturais, de acordo com as leis nacionais; 5.b Aumentar o uso de tecnologias de base, em particular as tecnologias de informação e comunicação, para promover o empoderamento das mulheres; 5.c Adotar e fortalecer políticas sólidas e legislação aplicável para a promoção da igualdade de gênero e o empoderamento de todas as mulheres e meninas, em todos os níveis.
}

Resenha Eleitoral (Florianópolis), v. 23, n. 1, p. 71-88, 2019 
A agenda internacional induz à "normalização" da igualdade de gêneros, tornando-se esse o comportamento social padrão. Ou seja, o "não natural" passa a ser a desigualdade. Trata-se de uma reconstrução profunda da percepção das estruturas sociais. A compreensão dessa questão é fundamental para perceber uma das principais barreiras apontadas por Pierre Muller no que se refere às políticas públicas de gênero que é, justamente, a de saber como agir sobre o comportamento antissocial.

Como abordar a esfera da privacidade que é construída a partir das relações sociais? Como se pode "governar" as relações de gênero? Como contribuir para ressignificar a intimidade da relação entre homens e mulheres e o papel de cada um no espaço público? Tais questionamentos são a chave para conseguir avaliar a eficácia dos instrumentos de políticas públicas nessas áreas (MULLER, 2015).

A abordagem do estudo está direcionada, portanto, para a contribuição que o poder público, através do seu sistema de controle, pode oferecer para o alcance deste que é um direito fundamental, a igualdade de gênero. Contribuir para a inclusão de uma identidade feminina reconhecida socialmente como relevante para a construção de um mundo pacífico, próspero e sustentável é o que se impõe aos Tribunais de Contas.

\subsection{A transversalidade da igualdade de gênero e seu impacto econômico-social}

O efeito multiplicador da igualdade de gênero é enfatizado no preâmbulo da Agenda 2030, que atesta que os objetivos nela definidos são integrados e indivisíveis, mesclando, de forma equilibrada, as três dimensões do desenvolvimento sustentável: a econômica, a social e a ambiental. Assim, o seu alcance contribuirá de forma decisiva para o progresso em relação a todos os demais objetivos e metas. $\mathrm{O}$ atendimento das metas estabelecidas pelo ODS 5 irá refletir diretamente na implementação de toda a Agenda 2030.

Do mesmo modo, há objetivos e metas, também abarcados pela Agenda 2030, correlatos ao ODS 5 e às metas a ele vinculadas, com conexões diretas com o seu alvo e cuja execução contribui para o seu alcance, passando por importantes questões, tais como o combate à pobreza e à fome, a promoção de educação e emprego, e a redução de desigualdades. 
O Instituto de Pesquisa e Economia Aplicada (Ipea) tem editado "cadernos" para divulgar estudos e pesquisas que visam contribuir para o alcance dos objetivos e metas definidos na Agenda 2030. Apesar de ainda não ter sido editado caderno específico para o ODS 5, pode-se observar no relativo ao ODS 10 (reduzir a desigualdade dentro dos países e entre eles) que o Ipea atesta que, mesmo se houver algum crescimento econômico, sem que haja uma melhoria substancial na distribuição da renda e da riqueza, torna-se mais difícil cumprir o objetivo de alcançar a igualdade de gênero e empoderar todas as mulheres e meninas (BRASIL, 2019a).

Isso evidencia que a integração entre os órgãos governamentais responsáveis pelas políticas públicas afetas à solução dos desafios sociais e econômicos é imprescindível para a obtenção de bons resultados. É preciso superar a visão de que cada Ministério ou Poder possua sua própria "agenda”, pois o enfrentamento das desigualdades exige que as políticas públicas que estão sob a responsabilidade de outros órgãos se comuniquem, sejam integradas e complementares.

Deve-se levar em consideração que o efeito multiplicador decorrente da natureza transversal do ODS 5 impacta tanto positivamente nos resultados das demais metas, como também dificulta o processo de fiscalização, na medida em que torna mais complexa a avaliação dos resultados das ações implantadas. Assim, paralelamente ao acompanhamento e à avaliação das medidas que são tomadas para o alcance das metas específicas do ODS 5, faz-se necessário também considerar a execução da Agenda 2030 como um todo, reconhecendo que a visão transversal das políticas de gênero é fundamental para a mitigação da desigualdade.

\subsection{Para onde estamos caminhando: os indicadores}

A Comissão Nacional para os Objetivos de Desenvolvimento Sustentável, criada por meio do Decreto (federal) n. 8.892/2016, atribuiu ao Ipea a função de assessoramento técnico permanente aos seus trabalhos. Assim, em decorrência dessa atribuição, em 2018 o Instituto promoveu a adequação das metas globais estabelecidas pela ONU à realidade brasileira, considerando suas características e especificidades, e definiu subsídios para a construção de indicadores para acompanhar o seu cumprimento.

A adequação levou em consideração as especificidades da cultura brasileira, conferindo relevo às populações consideradas marginalizadas do 
campo, da floresta, das águas e das periferias urbanas, cuja vulnerabilidade tem sido reiteradamente reconhecida pelo governo federal brasileiro ${ }^{6}$.

As metas podem ser subdivididas em dois grandes grupos. O primeiro grupo está direcionado para as ações que visem eliminar e inibir a discriminação e a repressão à violência. As ações estão voltadas ao agressor, como ocorre nas metas $5.1 ; 5.2 ; 5.3$. O segundo grupo destina-se às ações que visem à promoção da igualdade, sendo destinadas a políticas públicas que promovam a responsabilidade compartilhada e propiciem a inclusão feminina, como ocorre com as metas 5.4, 5.5 e 5.6 (BRASIL, 2018a).

Os subsídios do Ipea para a construção dos indicadores nacionais procuraram adequar essa adaptação a índices que demonstrem a implementação das metas em dados numéricos, mensuráveis pelos órgãos responsáveis.

De modo geral, em relação à meta 5.1, que pretende eliminar todas as formas de discriminação de gênero, foi definido como subsídio o "Percentual de órgãos da administração pública federal direta que implantaram os dispositivos do Decreto n. 8.727/2016, que dispõe sobre o uso e registro do nome social” (BRASIL, 2018a, p. 140).

Para a meta 5.2, que busca eliminar todas as formas de violência de gênero, foram estabelecidos como subsídios o "Percentual de meninas de até 15 anos sujeitas à violência sexual por pessoas conhecidas ou familiares nos últimos 12 meses, por idade, lugar de ocorrência e raça/cor" e a taxa de feminicídio (BRASIL, 2018a, p. 142).

Quanto à meta 5.3, que tem como objetivo eliminar práticas nocivas, como casamentos e uniões precoces, forçados e de crianças e jovens, o IPEA manteve como subsídio apenas o indicador global relativo ao "Percentual de mulheres com idade entre 20-24 anos que tenham sido casadas ou em união antes dos 15 e antes dos 18 anos" (BRASIL, 2018a, p. 143).

A meta 5.4, cujo escopo genérico é a eliminação da desigualdade na divisão sexual do trabalho, traz como subsídios para a construção de indicadores a proporção de atendimento de crianças e jovens pela rede de

\footnotetext{
${ }^{6}$ Política Nacional de Saúde Integral das Populações do Campo e da Floresta - 2013 (Ministério da Saúde), o Plano Nacional de Fortalecimento das Comunidades Extrativistas e Ribeirinhas 2017-2019 (Ministério do Meio Ambiente), o Conselho Nacional de Desenvolvimento Rural Sustentável - ODS - Metas Nacionais dos Objetivos de Desenvolvimento Sustentável CNDRS (Secretaria Especial de Agricultura Familiar e do Desenvolvimento Agrário) e o Conselho Nacional dos Povos e Comunidades Tradicionais - CNPCT (Ministério do Desenvolvimento Social).
} 
educação infantil e básica, e a avaliação da proporção de mulheres inativas, ou que não trabalham e estudam, por motivo de cuidados e afazeres domésticos, além da razão na participação no mercado de trabalho entre homens e mulheres (BRASIL, 2018a).

Quanto à meta 5.5, que visa garantir a participação plena e efetiva das mulheres e a igualdade de oportunidades para a liderança em todos os níveis de tomada de decisão na esfera pública, foi proposta a avaliação da proporção de mulheres entre candidatos e eleitos para mandatos no executivo e no legislativo, ocupantes de assentos em tribunais superiores ou em determinados cargos de confiança, além de outras posições de liderança (BRASIL, 2018a).

A meta 5.6, que trata de promoção, proteção e garantia da saúde sexual e reprodutiva, dos direitos sexuais e reprodutivos, teve proposta como subsídio para os indicadores a avaliação da cobertura e do atendimento à saúde feminina, novos casos de HIV, índice de mortalidade materna, incluindo o aborto, e legislação pertinente (BRASIL, 2018a).

Para as metas 5.a (garantia de igualdade de direitos, acesso e recursos econômicos), 5.b (garantia de igualdade no acesso, habilidades de uso e produção das tecnologias de informação e comunicação, do conhecimento científico e da informação, conteúdos de comunicação e mídias) e 5.c (fortalecimento das políticas públicas e da legislação) foi proposta a avaliação da participação da mulher nos sistemas pertinentes e a estruturação dos governos (BRASIL, 2018a).

A divulgação e a adoção de tais indicadores para a construção das matrizes de auditoria e para a apreciação dos processos de contas tornam-se fundamentais para a inserção dos Tribunais de Contas nesse processo.

\section{Os Tribunais de Contas como atores institucionais relevantes no processo de implementação do ODS 5}

Como um dos benefícios oriundos da adesão do governo brasileiro ao plano de ação internacional da Agenda 2030, destaca-se a definição de uma diretriz nacional que impõe a necessidade de integração das ações dos governos federal, estaduais e locais. A utilização dos mesmos indicadores, ou seja, da mesma linguagem para a mensuração do atendimento ou não aos Objetivos de Desenvolvimento Sustentável, representa um avanço para o alinhamento das políticas públicas. 
Nesse cenário, ganha relevo a atividade de controle realizada pelos Tribunais de Contas, cuja fiscalização deve contribuir para a eficiência e a eficácia das políticas públicas. Dentre suas competências, insere-se a realização de auditorias para a verificação da efetividade das ações governamentais, a partir da tradução do impacto desses indicadores em benefícios reais para a sociedade.

Contudo, inexiste no âmbito do controle externo qualquer definição nacional no sentido de estabelecer diretrizes para a fiscalização relativa ao ODS 5, tornando-se fundamental que essa temática seja objeto de estudos para a definição de diretrizes nacionais, bem como a formação de um Comitê de Gênero, que possam orientar a atuação dos 33 Tribunais de Contas, incluindo a construção de mecanismos que permitam supervisionar a implementação desse objetivo.

Ressalta-se que a formação de um Comitê de âmbito nacional é essencial para a adequação dos próprios processos e procedimentos internos dos Tribunais de Contas. A governança interna pressupõe o acompanhamento da representatividade feminina nos processos de liderança e a tomada de decisão e a verificação das políticas que estão sendo adotadas para superar eventuais discrepâncias.

De modo particular, o ODS 5 exerce papel relevante na construção de uma sociedade mais justa e solidária, na qual as mulheres possam exercer de modo simétrico e autônomo suas decisões, seja no âmbito familiar, no social ou no trabalho. Assim, comprometer-se e incluir-se nesse processo de articulação nacional é imprescindível para que os Tribunais de Contas possam desempenhar suas competências constitucionais de modo a cooperar com a efetividade das políticas públicas, estimulando ações e investimentos governamentais alinhados com os ODS.

\subsection{INTOSAI: programa auditando os objetivos de desenvolvi- mento sustentável}

Verifica-se que organismos internacionais têm atuado para a implementação e o monitoramento dos ODSs da Agenda 2030 da ONU. É o caso, por exemplo, da INTOSAI, que inseriu como uma de suas ações prioritárias o "Programa Auditando os Objetivos de Desenvolvimento Sustentável”, que contou com a adesão em âmbito nacional do TCU. 
Especificamente em relação ao ODS 5, o TCU instaurou um Processo de Auditoria Operacional n. TC 005.335/2018-3 com o objetivo de avaliar a preparação do governo brasileiro para implementar o ODS 5 da Agenda 2030 (BRASIL, 2018b). O escopo da referida auditoria restringiu-se em avaliar a preparação do governo federal brasileiro para implementar o ODS 5 no Brasil. A transversalidade do tema impôs a adoção de uma segunda premissa na definição do objeto dessa auditoria, qual seja, a de que a avaliação deve alcançar não só a preparação do governo para a implementação da política de gênero, mas também a consecução de outros objetivos e metas da Agenda 2030 que com esta guardem correlação.

No referido processo de auditoria operacional, foi adotada a metodologia estabelecida no Referencial para Avaliação de Governança em Políticas Públicas (BRASIL, 2014), o qual prevê oito componentes no modelo de avaliação: institucionalização, planos e objetivos, participação, capacidade organizacional e recursos, coordenação e coerência, monitoramento e avaliação, gestão de riscos e controle interno, e prestação de contas (accountability).

Observa-se que o processo anteriormente mencionado ainda tramita no TCU, com acesso público restrito e sem deliberação definitiva ${ }^{7}$. Assim, este estudo enfoca tão somente aspectos apontados no Relatório de fiscalização, cujo diagnóstico apresenta as deficiências e os desafios para estruturação do governo brasileiro, com o objetivo de atender ao ODS 5 (BRASIL, 2018a). Desse modo, não foram consideradas as propostas de encaminhamento da Relatora Ministra Ana Arraes que ainda serão objeto de julgamento pelo plenário do TCU.

A primeira questão refere-se às deficiências na montagem de estrutura de articulação entre órgãos. A importância da articulação e da integração foi constatada no âmbito da auditoria operacional, cujo relatório técnico evidenciou a necessidade de articulação entre órgãos nacionais (transversalidade horizontal), subnacionais (transversalidade vertical), bem como a importância da participação de parceiros privados.

De acordo com o apontado, a ampliação de uma perspectiva de focalização setorial para a de integração entre setores é necessária, a fim de que a política de gênero seja efetiva. Isso implica a necessidade de realização

\footnotetext{
${ }^{7} \mathrm{O}$ acesso restrito que impede a visualização do Relatório técnico deve ser pontuado como um limitador da pesquisa. No entanto, para obter as informações necessárias para a elaboração do referido estudo foram obtidos os dados diretamente na Secretaria Nacional de Políticas para as Mulheres (SNPM).
} 
de acordos e fomento de sinergias entre diversos atores. Foram constatadas, ainda, a deficiência e a descontinuidade nas estruturas de articulação ${ }^{8}$. A ausência de normas diretivas como regimento interno, ou mesmo a ausência na definição de núcleos temáticos, contribui de modo significativo para tais deficiências.

A segunda questão decorre da necessidade de monitoramento, avaliação e elaboração de relatórios reportando o avanço em relação à implementação, de modo a contribuir para o aperfeiçoamento dos planos de ação a partir de uma visão integrada com o sistema de controle. A não incorporação da preocupação com igualdade de gênero nas principais políticas públicas que afetam as mulheres foi apontada como uma das deficiências relevantes. A neutralidade das políticas em relação às questões de gênero, seja em política educacional, seja em segurança pública, constitui um dos obstáculos a serem superados e que devem ser incluídos na matriz de fiscalização dos Tribunais de Contas.

A terceira questão é inerente às fraquezas dos sistemas de dados e de seu impacto no monitoramento das políticas para as mulheres. De acordo com o TCU, a amplitude da Agenda 2030 pressupõe um grande número de indicadores, com o maior nível de desagregação possível, para a medição do avanço do desenvolvimento sustentável. Em relação às questões relacionadas com mulheres, os desafios são grandes, em especial pelas políticas setoriais não serem desenhadas sob a perspectiva de gênero. Dessa maneira, há dificuldade de se captar as diferenças de impactos em temas como pobreza ou violência doméstica.

Além das dificuldades intrínsecas aos fenômenos relacionados às políticas para as mulheres, destaca-se o enfraquecimento das estruturas destinadas ao seu desenvolvimento no que se refere à estruturação física e à capacidade operacional, o que dificulta a coleta e a análise de dados sobre o tema, impacta no monitoramento e na avaliação da política pública, e prejudica o seu aperfeiçoamento.

Com relação às fiscalizações que abordaram a violência contra a mulher relacionada à Meta 5.2, o TCU realizou auditoria operacional que teve como objetivo avaliar as ações de enfrentamento à violência domés-

\footnotetext{
${ }^{8} \mathrm{Na}$ auditoria, foi considerado o Comitê de Articulação e Monitoramento do PNPM (CAM), instituído por meio dos arts. 3a a 5º do Decreto 7.959, de 13 de março de 2013. Da mesma forma, a instituição da Rede Brasil Mulher, através do Decreto (federal) 9.223/17, foi considerada uma das ações implementadas para atender a tal necessidade.
} 
tica e familiar contra as mulheres, mais especificamente se os mecanismos previstos na Lei n. 11.340/2006 (Lei Maria da Penha) funcionam adequadamente, e quais restrições podem ser observadas em relação às ações de atenção integrada e qualificada prestadas às mulheres vítimas de violência.

Por meio do Acórdão n. 403/2013 - TCU - Plenário, foram encaminhadas recomendações à Secretaria de Políticas para as Mulheres (SPM), à Secretaria Nacional de Segurança Pública (Senasp) e à Secretaria de Reforma do Judiciário (SRJ), no sentido de fortalecer o sistema de atendimento às mulheres vítimas de violência; propiciar a articulação entre os atores que compõem a rede de atendimento; e enfrentar os principais problemas que foram identificados, quais sejam, o da deficiência no número de unidades e concentração nas metrópoles; o do déficit no quantitativo de recursos humanos para atividades de apoio e multidisciplinares; o da falta de sensibilização dos operadores da rede quanto às questões de gênero; e o da falta de treinamento em relação à Lei Maria da Penha.

No âmbito do Tribunal de Contas do Estado de Santa Catarina, o primeiro processo a trazer uma análise específica ao ODS 5 foi o RLA 18/01156694, por meio do qual foi avaliado o custo econômico dos casos de feminicídio ocorridos no estado catarinense entre 2011 e agosto de 2018. Foram considerados os impactos em produtividade (redução na capacidade de trabalhar e poder contribuir para a sociedade), trauma (impacto sobre a saúde mental dos envolvidos) e serviços públicos (setores em que ocorre necessidade de alocação de recursos em detrimento de outros). De modo conclusivo, foi estimada perda socioeconômica de $\mathrm{R}$ \$ 424,3 milhões ao Estado de Santa Catarina, com a ressalva de que, em face da ausência de dados para vários custos envolvidos, o valor mensurado foi considerado uma estimativa mínima, uma vez que a perda socioeconômica pode ser ainda mais expressiva (SANTA CATARINA, 2018).

O que se percebe, portanto, é que os indicadores devem ser utilizados pelos órgãos de controle para subsidiar suas fiscalizações de modo a contribuir com a implementação do ODS 5, buscando sempre direcionar seus esforços para uma atuação integrada. Assim, os dados obtidos ou mesmo a utilização de novos parâmetros podem contribuir para a efetividade no que se refere ao atendimento das metas. 
No entanto, conclui-se com esta pesquisa que há um processo ainda incipiente no que se refere à fiscalização do ODS 5 no âmbito dos Tribunais de Contas 9 .

Desse modo, torna-se primordial que os Tribunais de Contas participem do processo de articulação e construção de mecanismos estruturados e sistematizados de compartilhamento de dados.

\section{As propostas normativas que objetivam a promoção da igualdade de gênero}

A promoção da igualdade de gênero passa também pelo estabelecimento de garantias e diretrizes normativas para a participação das mulheres nos diversos níveis da esfera decisória e política.

No campo normativo tramita, no Senado Federal, o Projeto de Lei n. 2235/2019, de autoria do Senador Luiz do Carmo (MDB/GO), que visa alterar o Código Eleitoral (Lei n. 4.737/1965) para estabelecer a reserva de ao menos trinta por cento das cadeiras de Deputado Federal, Deputado Estadual, Deputado Distrital e Vereador para cada um dos sexos e reservar, quando da renovação de dois terços do Senado Federal, uma vaga para candidaturas masculinas e outra vaga para candidaturas femininas (BRASIL, 2019b).

A alteração deve propiciar que ao menos trinta por cento das vagas nas eleições proporcionais sejam ocupadas por pessoas de sexos distintos e que na renovação de dois terços dos membros do Senado Federal seja garantida a eleição de um representante de cada sexo.

Destaca-se também o Projeto de Lei n. 7.179/2017, em tramitação na Câmara dos Deputados, que dispõe sobre a participação de mulheres nos Conselhos de Administração das Empresas Públicas e Sociedades de Economia Mista, suas subsidiárias e controladas, e demais empresas em que a União, direta ou indiretamente, detenha a maioria do capital social com direito a voto, de autoria da Senadora Maria do Carmo Alves (BRASIL, 2017).

Propõe-se, em seu artigo $2^{\circ}$, que seja assegurada a participação de, no mínimo, 30\% (trinta por cento) de mulheres entre os membros titulares

\footnotetext{
${ }^{9}$ Para uma análise mais profunda sobre o processo de controle das políticas públicas, vide IOCKEN, Sabrina Nunes. Controle Compartilhado de Políticas Públicas. Belo Horizonte: Fórum, 2018.
} 
nos Conselhos de Administração das Empresas Públicas, das Sociedades de Economia Mista e das entidades de representação civil, como Oscips, Sindicatos, fundações, associações e organizações similares, pelo menos 30\% (trinta por cento) dos membros titulares serão mulheres.

Ainda nesse sentido, em 2018, quando ocorreram as últimas eleições, o Tribunal Superior Eleitoral (TSE) garantiu a aplicação de no mínimo 30\% dos recursos do Fundo Especial de Financiamento de Campanha e do tempo de propaganda gratuita no rádio e na TV para as mulheres candidatas.

Foi editada a Resolução - TSE n. 23.575/2018, que alterou a regra anterior (Resolução - TSE n. 23.553/2017), para garantir que os partidos políticos destinem ao financiamento de campanhas de suas candidatas no mínimo 30\% dos gastos totais contratados nas campanhas eleitorais com recursos do Fundo Partidário (BRASIL, 2018c).

Trata-se de medidas por meio das quais se busca alterar o status quo vigente, mas que demandam a efetiva implementação e o acompanhamento para que se traduzam em conquistas reais para a representatividade das mulheres em todos os níveis de tomada de decisão na esfera pública, em suas dimensões política e econômica.

\section{Considerações finais}

A (re)construção da identidade social feminina pressupõe a existência de relações sociais pautadas pelo olhar subjetivo da igualdade, o que exige uma mudança coletiva cultural, alicerçada pela percepção individual inclusiva para a estruturação de novas relações simétricas entre homens e mulheres (SALAZAR, 2018).

Deve-se ter em conta que a implementação do ODS 5 compreende tanto a dimensão negativo-repressiva como uma dimensão positiva, indutora de uma maior participação das mulheres nas esferas política, econômica ou social. O recorte deste estudo foi direcionado para verificar como os Tribunais de Contas estão inserindo em suas fiscalizações a verificação do atendimento do ODS 5.

A transversalidade da igualdade de gênero e seu impacto econômico-social são percebidos pela Agenda da ONU como fundamentais para o alcance em relação a todos os objetivos e metas, de modo que o impacto em relação ao seu atendimento refletirá diretamente na mensuração de toda 
a Agenda 2030. Assim, se por um lado, o efeito multiplicador decorrente da natureza transversal do ODS 5 pode implicar impactos positivos nos resultados das demais metas, por outro lado, essa natureza transversal dificulta o processo de fiscalização, na medida em exige uma análise complexa e integrada dos resultados das ações implantadas.

Desse modo, cabe aos Tribunais de Contas se inserirem como atores institucionais relevantes no processo de implementação do ODS 5. No plano internacional, o "Programa Auditando os Objetivos de Desenvolvimento Sustentável”, promovido pela INTOSAI, já começou a ser replicado no âmbito do TCU, através da realização de auditoria operacional para avaliar a preparação do governo brasileiro visando implementar o ODS 5 da Agenda 2030.

Do diagnóstico apurado pela respectiva auditora operacional, cabe apontar três questões: i) deficiências na montagem de estrutura de articulação entre órgãos; ii) necessidade de monitoramento, de avaliação e da elaboração de relatórios de avanço de modo a contribuir para o aperfeiçoamento dos planos de ação, a partir de uma visão integrada com o sistema de controle; e iii) fraquezas dos sistemas de dados que impactam no monitoramento das políticas para as mulheres.

Contudo, destaca-se a inexistência de diretrizes nacionais que norteiem a atuação dos Tribunais de Contas sobre a implementação do ODS 5 , o que demonstra a importância de que sejam realizados estudos e estabelecidos parâmetros para o monitoramento. O que não se pode conceber é que órgãos de controle se mostrem refratários às metas estabelecidas pelos ODS, tanto no que se refere à sua própria estrutura interna quanto às diretrizes para a fiscalização.

Como visto, os Tribunais de Contas podem desempenhar um papel relevante de orientação ao Executivo e aos demais poderes envolvidos na implementação da Agenda 2030. A efetividade no cumprimento dos objetivos e das metas estabelecidos depende da articulação dos diferentes órgãos e poderes para que cada um, segundo suas competências, possa contribuir com a promoção do desenvolvimento sustentável.

Eis o nosso afiado desafio. 


\section{Referências}

BRASIL. Tribunal de Contas da União. Referencial para Avaliação de Governança em Políticas Públicas. Brasília: TCU, 2014. Disponível em: https://portal.tcu.gov.br/lumis/portal/file/ fileDownload.jsp?fileId=8A8182A15232A37901529D144765541F. Acesso em: 14 jul. 2019.

BRASIL. Câmara dos Deputados. Dispõe sobre a participação de mulheres nos conselhos de administração das empresas públicas e sociedades de economia mista, suas subsidiárias e controladas e demais empresas em que a União, direta ou indiretamente, detenha a maioria do capital social com direito a voto. Projeto de Lei n. 7.179/2017. Brasilia, 2017. Disponível em: https://www.camara.leg.br/proposicoesWeb/fichadetramitacao?idProposicao=2126313. Acesso em: 15 jul. 2019.

BRASIL. Instituto de Pesquisa Econômica Aplicada. Agenda 2030: ODS Metas Nacionais dos Objetivos de Desenvolvimento Sustentável. Brasília: Ipea, 2018a. Disponível em: http://www.ipea.gov.br/portal/images/stories/PDFs/ livros/livros/180801_ods_metas_nac_dos_obj_de_desenv_susten_propos_ de_adequa.pdf. Acesso em: 10 jul. 2019.

BRASIL. Tribunal de Contas da União. Auditoria Operacional TC 005.335/2018-3. 2018b. Disponível em: https://pesquisa.apps.tcu.gov.br/\#/ documento/processo/*/PROC $\% 253$ A533520183/ANO $\% 20$ desc, $\% 20$ NUMEROPROCESSOCOMZEROS $\% 20 \mathrm{desc} / 0 / \% 20$ ?uuid=6def5bb0-a731-11e9-bd1a-498523788b4f. Acesso em: 14 jul. 2019.

BRASIL. Tribunal Superior Eleitoral. Altera a Resolução-TSE n. 23.553, de 18 de dezembro de 2017, que dispõe sobre a arrecadação e os gastos de recursos por partidos políticos e candidatos e sobre a prestação de contas nas eleições. Resolução n. 23.575, de 28 de junho de 2018. Brasília, DF, 2018c. Disponível em: http://www.tse.jus.br/legislacao-tse/res/2018/RES235752018.html. Acesso em: 15 jul. 2019.

BRASIL. Instituto de Pesquisa Econômica Aplicada. ODS 10: Reduzir a Desigualdade Dentro dos Países e Entre Eles. Brasília: Ipea, 2019a. Disponível em: http://www.ipea.gov.br/portal/images/stories/PDFs/livros/livros/190524_ cadernos_ODS_objetivo_10.pdf. Acesso em: 14 jul. 2019.

BRASIL. Senado Federal. Altera a Lei n. 4.737, de 15 de julho de 1965 (Código Eleitoral), para estabelecer a reserva de ao menos trinta por cento das cadeiras de Deputado Federal, Deputado Estadual, Deputado Distrital e Vereador para cada um dos sexos e reservar, quando da renovação de dois terços do Senado Federal, uma vaga para candidaturas masculinas e outra vaga para candidaturas femininas. Projeto de Lei n. 2235, de 2019. Brasília, DF, 2019b. Disponível em: https:/ /www25.senado.leg. br/web/atividade/materias/-/materia/136302. Acesso em: 15 jul. 2019. 
CASTELLS, Manuel. O poder da identidade. (trad.) Klauss Brandini Gerhardt. 8. ed. São Paulo: Paz e Terra, 2013.

DEAN, Michelle. Afiadas: as mulheres que fizeram da opinião uma arte. São Paulo: Todavia, 2018, p. 299.

IOCKEN, Sabrina Nunes. Avaliação das políticas públicas: necessidade de uma diretriz normativa no âmbito dos Tribunais de Contas, In: LIMA, Luiz Henrique; SARQUIS, Alexandre Manir Figueiredo (Coord.). Processos de Controle Externo: Estudos de ministros e conselheiros substitutos dos Tribunais de Contas. Belo Horizonte, 2019, p. 263-286.

IOCKEN, Sabrina Nunes. Controle Compartilhado de Políticas Públicas. Belo Horizonte: Fórum, 2018.

MUlLER, Pierre. Les Politiques Publiques. 11. ed. Paris: Presses Universitaires de France, 2015, e-book.

ONU. Transformando Nosso Mundo: A Agenda 2030 para o Desenvolvimento Sustentável. Disponível em: https://nacoesunidas.org/wp-content/ uploads/2015/10/agenda2030-pt-br.pdf. Acesso em: 09 jul. 2019.

SALAZAR, Octavio. El hombre que no deberíamos ser: la revolución masculina que tantas mujeres llevan siglos esperando. Barcelona: Planeta, 2018.

SANTA CATARINA. Tribunal de Contas do Estado. RLA 18/01156694. 2018. Disponível em: http://servicos.tce.sc.gov.br/processo/index.php. Acesso em: 14 jul. 2019.

Sabrina Nunes Iocken - Doutora em Direito pela Universidade Federal de Santa Catarina - UFSC (2017) e Conselheira Substituta do TCE/SC (2006).

Luciane Beiro de Souza Machado - Mestranda em Políticas Públicas - UDESC, graduada em Direito - UFSC (1996), graduada em Administração (1995). Auditora de controle externo do TCE/SC. 